\title{
Viscoplastic Parametric Analysis of Cylindrical Specimen Under Cyclic Behaviour
}

\author{
Panagiotis J. Charitidis \\ Environmental Engineering School, Democritus University of Thrace, Xanthi, Xanthi, Greece
}

\begin{abstract}
Article Info

Volume 8 Issue 1

Page Number: 75-82

Publication Issue :

January-February-2021

\section{Article History}

Accepted : 10 Jan 2021

The present study tries to present a cyclic hardening model with the aim to simulate quantitatively the material response under strain controlled cyclic loading in tension-compression, of specified axial deformation. A numerical study was carried out to investigate the cyclic constitutive behaviour of alloy Indium under viscoplastic deformation. The analysis was performed under prescribed symmetric strain-controlled cyclic loading. The model contains both isotropic and kinematic hardening components, while the analysis were performed using Comsol Multiphysics for only 60 seconds duration. The kinematic hardening was described by using multiple back stresses. Multiple back stresses can provide a smoother transition between the elastic and plastic deformation, and it improves the general shape of the hysteresis loop. Two cases (geometries) have been examined in this study. From the material model and finite element cyclic plasticity model results, it is found that for the same parameters, but different dimensions there is difference on the stress-strain curves as well as on the von Mises stresses.
\end{abstract}

Published : 22 Jan 2021
Keywords: Indium Alloy, Cycling Loading, Viscoplasticity, Comsol Multiphysics

\section{INTRODUCTION}

It is well known, that for structural safety, the control of progressive strain accumulation is of fundamental importance. One of the major topics to be investigated are the life predictions techniques for large deformation structure designs. It is well known that both creep deformations cyclic plasticity as well as cyclic plasticity tends structures to failure. It has been mentioned that for the cases of specimens with notches or welds, the cyclic loading may induce stresses more than elastic limit of the material. For instance, the material 316SS where during experimental procedure may become inelastic and may exhibit related phenomena such as the Bauschinger effect, cyclic hardening/softening, and mean stress relaxation or ratcheting [1]. However, in order to describe the above cyclic plasticity phenomena numerous material parameters are needed [2, 3]. The literature review shows that most models were applied to simulate uniaxial and multiaxial strain ratcheting effects observed in stress or in mixed-control deformation programs [4]. Moreover, several material models [1,5] have been developed to describe the cyclic plasticity behavior of materials under different loading conditions. This has 
also been explored in prior studies by Chaboche $[6,7]$ and Armstrong- Frederick [8] law. A closer look to the literature on Armstrong- Frederick law and its multi segmented version due to Chaboche and Rousselier were limited only to saturated state. Despite of that the above models can be found in several commercial software, such as Ansys, Abaqus and Comsol Multiphysics. It will be noted that the accuracy of results depends on the capability of the material model $[9,10]$. That means, the cyclic plasticity theories must be understood before using such commercial software's, especially for specimens with the presence of welds and notches [11-17]. In previous studies were showed to the limitation of Chaboche model in predicting mean stress relaxation behaviour at a different total strain ratio [18]. Most studies have relied on Chaboche model. A recent study by Liu and Liang [19] concluded that using Chaboche material model for optimizing material parameters (included initial yield stress) plays crucial role for model optimization. Some authors have also suggested that the Chaboche material model could be used to predict the micromechanical response in dual phase steels with three back stress terms [20, 21]. Isotropic hardening rate cyclic hardening could be explained by using a strain memory surface which was introduced by Dang Van and Cordier [22]. Their model was modified by Ohno and Kachi [23] to achieve more realistic model, but the main problem was fading memory.

Additional studies to understand more completely the key tenets of understanding of the cyclic plasticity of metal are required. An interesting approach was presented by Meggiolaro et al. [24], by using the concept of Tanaka [25]. To give some idea of the benefits of this method a new integral was developed for the nonproportionality factor of periodic loadings. They also introduced a unified approach to the modelling of nonlinear kinematic hardening represented in the five-dimensional space $[26,27]$ which was reproduced by Mroz,[28]. In his study, the plastic modulus calculation is not coupled to the kinematic hardening rule through the consistency condition as in the previous cases, but it still might be indirectly influenced. Hence, the so-called uncoupled model.

As it can be seen, there is a wide choice of models available in the literature. Most models are based on the concept of interaction of hardening and dynamic recovery effects. Back stress is a quite useful variable because can be increased along the plastic strain rate orientation and decreased proportionally to the backstress measure. In effect, the back stress evolves toward its limit value specified by the hardening saturation surface $[7, \underline{8}, 29-36]$. From the models [2936], it was shown that the back stress evolution rules of those two classes of models are equivalent [37], [표] . A notable success was achieved by developing simplified two-surface hardening models for which the variation of plastic hardening modulus was prescribed analytically by Dafalias and Popov [39], Tseng and Lee [40], McDowell [41]. It was reported in literature that hardening moduli was provided by assuming continuous field of yield surfaces [42]. Furthermore, for multisurface hardening plasticity cases, numerical model was introduced by Khoei and

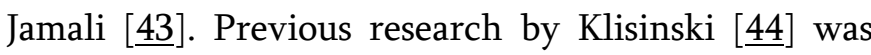
used to simulate the fuzzy set of the cyclic response for a continuous field of loading surfaces.

The purpose of this study is to conduct a finite element analysis for a certain material in order to allow useful comparison between the two geometries. The stress-strain data have been obtained from several stabilized cycles of specimens that are subjected to symmetric strain cycles [45]. A combined model was used, while the axial strain was ranged between -0.5 to $0.5 \%$. 


\section{MATERIAL METHODS AND METHODS}

\section{A. Material and Specimen Configuration}

For this study, the material was been considered was the low melting Indium alloy which will often be used in cases of bending, anchoring, chuck, or jig applications. The specimen used for this analysis is of cylindrical shape having a radius of $\mathrm{d}=10 \mathrm{~mm}$ and half length of $100 \mathrm{~mm}$ (half length $\mathrm{L}_{\mathrm{o}}=50 \mathrm{~mm}$ ), as shown in figure 1 . The material properties of the selected material are given in Table 1.

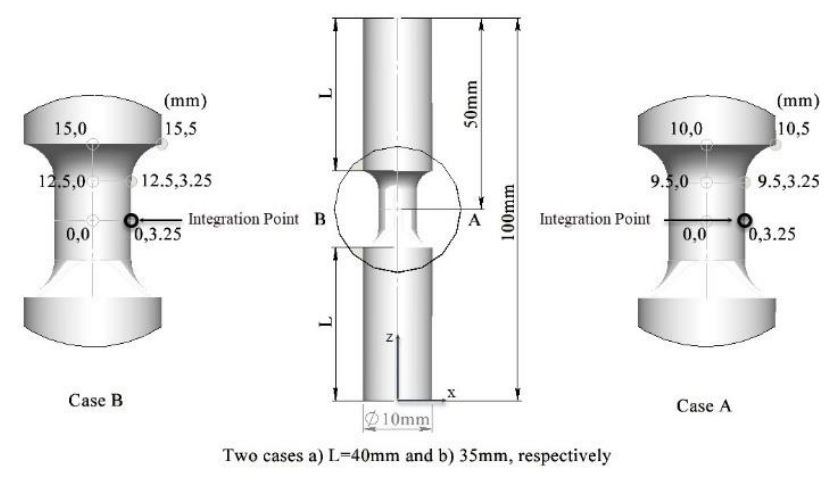

Figure 1: Specimen configuration

TABLE I

MATERIAL PROPERTIES

\begin{tabular}{|c|c|}
\hline Young Modulus (GPa) & 200 \\
\hline Poission Ratio & 0.3 \\
\hline Density (kg/m3) & 7500 \\
\hline Initial Yield Stress (MPa) & 60 \\
\hline Reference Stress (MPa) - Chaboche & 490 \\
\hline Stress Exponent- Chaboche & 9 \\
\hline Prescribed strain rate eot (1/s) & 0.001 and \\
\hline Initial Kinematic Hardening \\
Parameter(go) & 1200 \\
\hline Saturation Kinematic Hardening \\
Parameter (gs)
\end{tabular}

\begin{tabular}{|c|c|}
\hline $\begin{array}{c}(1 / \mathrm{s}) \text { - Chaboche } \\
\text { Saturation Flow Stress }(\mathrm{MPa})-\end{array}$ & -35 \\
Voce & 200 \\
Saturation Exponent - Voce & 362.5 \\
\hline $\begin{array}{c}\text { Kinematic Hardening modulus } \\
(\mathrm{GPa}) \text { Armstrong - Frederick }\end{array}$ & \\
\hline
\end{tabular}

\section{B. Finite Element Method}

The FE simulation of the model is implemented on a round bar specimen under prescribed symmetric strain $( \pm 0.5 \%)$, controlled tension compression loading (cycling loading). An elasto - plastic finite element model was developed in Comsol Multiphysics, and a combined model was adopted for hardening criterion, in order to simulate the inelastic behaviour of the material. This model includes both isotropic hardening and kinematic hardening. One of the key benefits of the model is that the isotropic hardening model predicts shakedown behavior unless creep is considered. On the other hand, kinematic hardening was also selected for both cases because specimens were subjected to repeated loading. One primary problem with isotropic hardening is that model hardens during cyclic loading. Moreover, in the kinematic hardening models, the center of the yield surface moves in the stress space due to the kinematic hardening component, while the combination of the nonlinear isotropic/kinematic hardening model tends the yield surface range to expand due to the isotropic component. The most important advantage of these models is that it can perform very well in modeling of inelastic deformation in metals that are subjected to cycles of load or temperature. To give some idea of the benefits of this method is that the both nonlinear kinematic hardening as well as isotropic hardening component could described the translation of the yield surface in the stress space through the back-stress, and the change of the equivalent stress defining the size of the yield surface as a function of plastic deformation, respectively. In this study, the hardening rules 
considered are the Chaboche model including the kinematic and isotropic hardening effects. For shortening the computation time, half of the specimen is modeled in a 2D axisymmetric geometry. The step size was 0.005 (from 0 to 1). The axial velocity (z-direction) was constant while the loading type was described as 1 to represent axial tension and -1 to represent axial compression. The number of elements were 104.903, for both cases while the boundary conditions are shown in figure 2 .

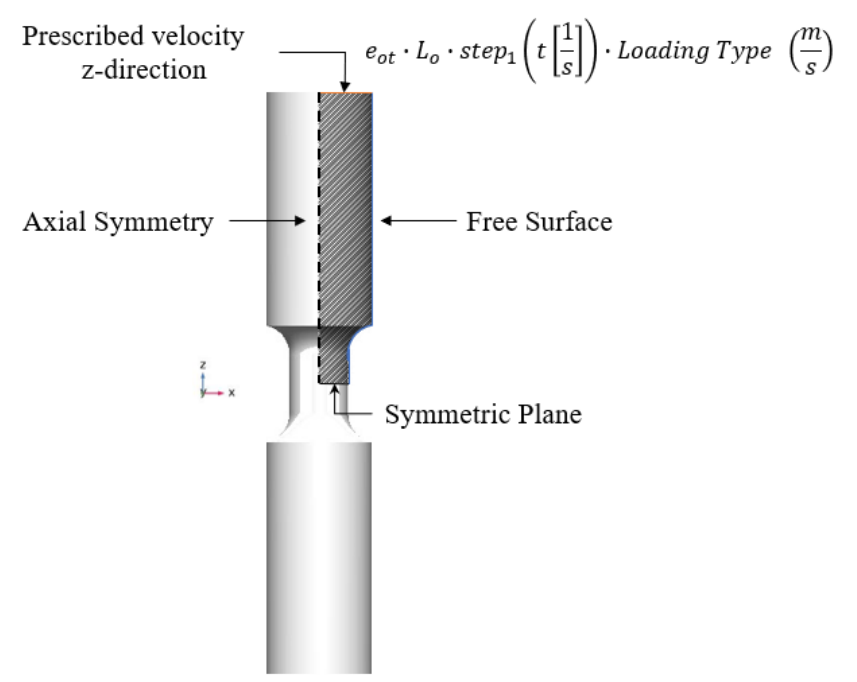

Figure 2: Boundary Conditions

\section{III.RESULTS AND DISCUSSION}

To illustrate model performance, consider the uniaxial cyclic behavior. Figure $3 \mathrm{a}$ and $\mathrm{b}$ presents the evolution of back stresses vs time $(60 \mathrm{sec})$ for 0.001 $(1 / \mathrm{s})$ and $0.01(1 / \mathrm{s})$ strain rate, respectively. The multiple back stress superposition method is adopted for fitting the curve more accurately which offers a smoother transition between the elastic and plastic deformation, and it improves the general shape of the hysteresis loop. The saturated value of back stress in tension and compression for both cases are presented in table 2. As it can be observed from table 2, by increasing the strain rate from $0.001(1 / \mathrm{s})$ to $0.01(1 / \mathrm{s})$, the results shown that tensile values are lower than compression (table 2, case A). However, for the second case, tensile values are greater than compression. There is a visible deformation and necking of the specimens and it is expected that during the experimental procedure the failure process will be very sudden (figure 4 ).

The deformation as well as the necking of the specimens tends to change the stresses at the critical locations. For instance, figure $5 \mathrm{a}, \mathrm{b}$ shows the Von mises stress distribution as a schematic representation of 10 levels (iso-surface). The simulated curves have difference between the stain rates under cyclic loading. At critical locations (Integration point, figure 1) with a low stress concentration, the effect of strain ratchetting would be more severe, if it exists at all, because in this case the plastic deformation is less constrained. Generally, the back stress is proportional to plastic strain [46], while the response is symmetric with zero mean back stress. After the first tensile cycle the axial stress (figure $6 a$ and $b$ ) increases linearly, exceeding the yield strength (60 MPa).
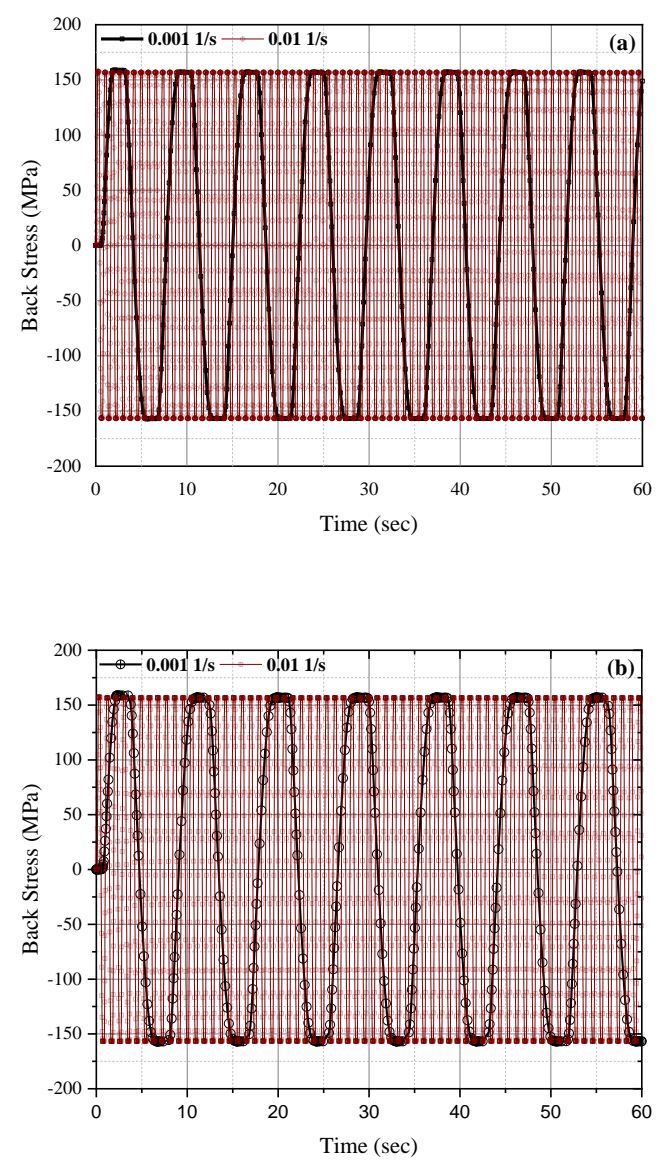

Figure 3: Back stress curves for case a and b, for two different strain rates. 
TABLE II

BACK STRESS - AVERAGED RESULTS

\begin{tabular}{|c|c|c|c|c|}
\hline Strain Rate & \multicolumn{2}{|c|}{ Case A (MPa) } & \multicolumn{2}{c|}{ Case B (MPa) } \\
\hline $0.001(1 / \mathrm{s})$ & 154.82 & -156.89 & 157.31 & -156.67 \\
\hline $0.01(1 / \mathrm{s})$ & 155.23 & -156.73 & 156.92 & -121.55 \\
\hline
\end{tabular}

During the analysis, stresses and strains results are stored in a table along with all the model internal variables as a function of time $(60 \mathrm{sec})$ in Comsol Multyphysics [47].

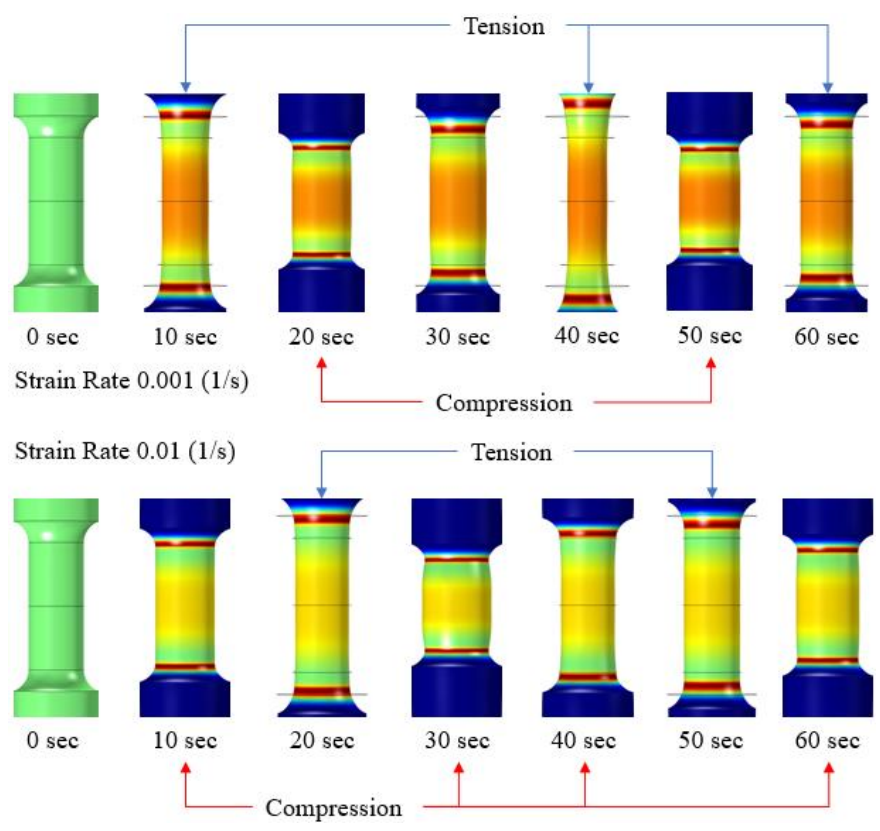

Figure 4: Viscoplastic strain analysis for case a as a function of time.
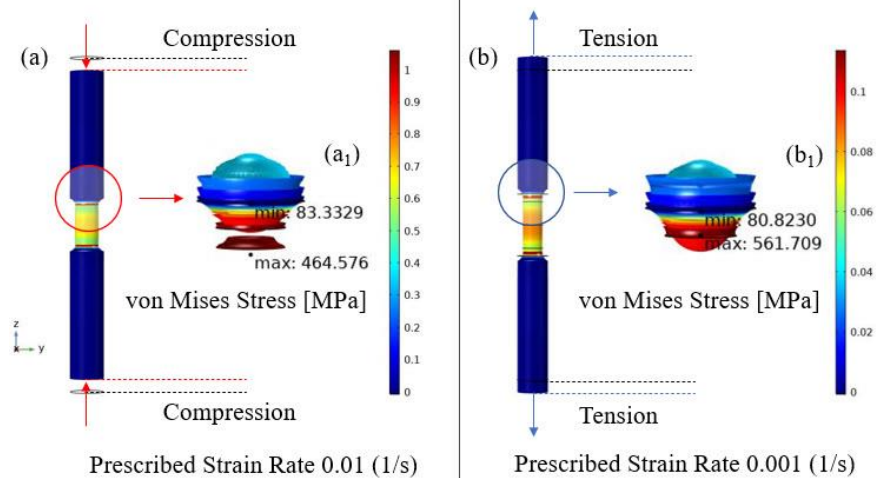

Prescribed Strain Rate $0.001(1 / \mathrm{s})$
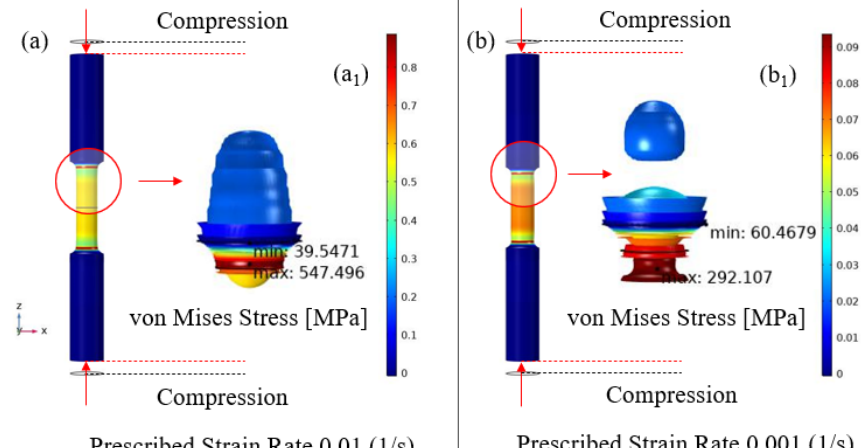

Prescribed Strain Rate $0.01(1 / \mathrm{s})$

Prescribed Strain Rate $0.001(1 / \mathrm{s})$

(b)

Figure 5: Von Mises stresses for different strain rates at 60 seconds for a) case a and b) case b.

There is in fact sufficient information present in figures $6 a$ and $b$. The figures show reversed plasticity after some transient cycles of load for the Chaboche where the axial strain was cycled through -0.5 to $0.5 \%$. As it can be seen for both cases there is a closely match after the first one or two reversal, which means that errors are not accentuated. It is interesting to note that, the relation between stress and strain is no longer linear, kinematic/isotropic hardening evolves, and the back-stress increases (figure 3a, b). During the analysis was observed that the yield strength in compression is lower than the initial one.

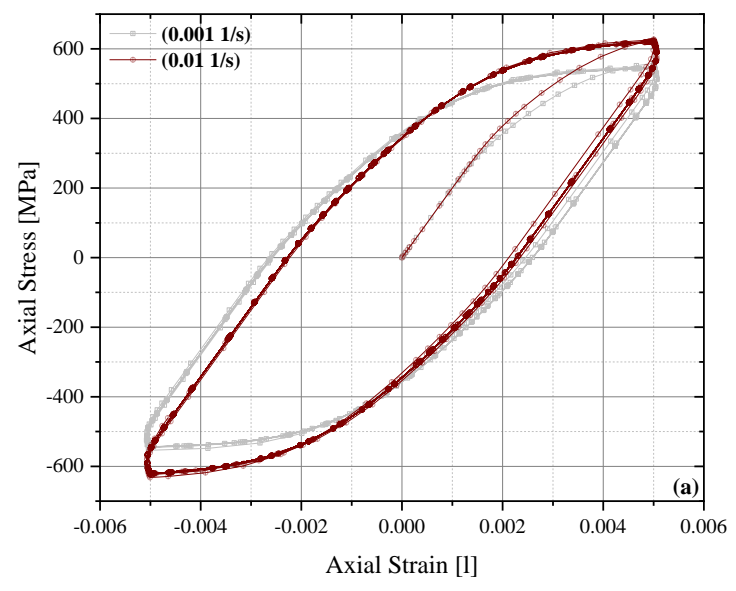

(a) 


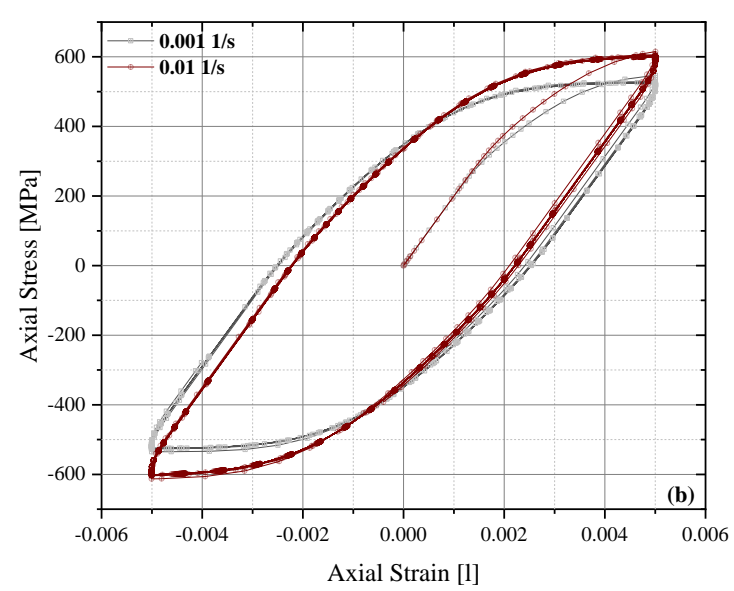

Figure 6: Axial strain vs. stress for case a and $b$.

This allows the conclusion that the viscoplastic flow starts earlier and lasts for a longer period. After that period the prescribed velocity becomes positive in order to prescribe tensile loading. In other words, for each half cycle, the isotropic component initially softens, then hardens. At the cyclically stable state (depends upon the strain limits), these two casesmodels predict that the isotropic component has its maximum saturation value, the value that it would achieve at large strain in a compression test. For a larger hysteresis loop, a greater amount of hardening takes place, and the isotropic component is larger. This means that for predicting cyclic plasticity, the isotropic component of stress depends upon the strain limits as a function of time (figure $6 \mathrm{a}, \mathrm{b}$ ). Moreover, for small to large strain regimes, monotonic loading is an important feature where the isotropic component can reach a much greater value than for small to moderate strain cyclic plasticity.

\section{IV.CONCLUSION}

The findings of this study can be understood as, Chaboche model including the kinematic and isotropic hardening effects. During the analysis was observed the translation of the yield surface in the stress space through the back-stress, and the change of the equivalent stress defining the size of the yield surface as a function of plastic deformation. The evidence from this study suggests that Chaboche model predicts shakedown for the cycled deformation-controlled stresses. This could eventually lead to the reversed plasticity. During the analysis (for both cases) all the important stages of material behaviour were mechanically captured as well as the stiffness degradation and strength degradation.

\section{REFERENCES}

[1]. J. Shit, S. Dhar and S. Acharyya. 2013. Procedia Engineering. DOI: /10.1016/j.proeng.2013.03.330

[2]. O.T. Bruhns. "Some remarks on the history of plasticity - Heinrich Hencky, a pioneer of the early years", Lecture Notes in Applied Mathematics and Mechanics, Vol.1 (2014a), pp.133-152.

[3]. O. T. Bruhns. 2014b. Zeitschrift für Angewandte Mathematik und Mechanik,. DOI: /10.1002/zamm.201300243

[4]. J.L. Chaboche, P. Kanoute, and F. Azzouz. 2012. International Journal of Plasticity. DOI:10.1016/j.ijplas.2012.01.010

[5]. N. Ohno and J. D. Wang. 1993. International Journal of Plasticity.

[6]. J. L. Chaboche.1986. International Journal of Plasticity. DOI: /10.1016/0749-6419(86)90010-0

[7]. J. L. Chaboche. 1991. International Journal of Plasticity. DOI: /10.1016/0749-6419(91)90050-9

[8]. P. J. Armstrong and C. O. Frederick. 1966. “A Mathematical Representation of the Multiaxial Bauschinger Effect," Central Electricity Generating Board and Berkeley Nuclear Laboratories, Research \& Development Department.

[9]. L. Moro, D. Benasciutti and F. De Bona. 2019. Ironmaking Steelmaking. DOI:/10.1080/03019233.2017.1339482

[10].L. Moro, J. Srnec Novak, D. Benasciutti and F. De Bona. 2019. Ironmaking Steelmaking. DOI:/10.1080/03019233.2017.1371425 
[11].S. Mohanty, W. K. Soppet, S. Majumdar and K. Natesan. 2015. "Effect of Pressurized Water Reactor Environment on Material Parameters of 316 Stainless Steel: A Cyclic Plasticity based Evolutionary Material Modeling Approach," ASME Pressure Vessels and Piping Conference, PVP2015 45701.

[12].S. Mohanty, W. K. Soppet, S. Majumdar and K. Natesan. 2016. Nuclear Engineering and Design. DOI:/10.1016/j.nucengdes.2016.05.031

[13].S. Mohanty, W. K. Soppet, S. Majumdar and K. Natesan. 2015. "Tensile and Fatigue Testing and Material Hardening Model Development for 508 LAS Base Metal and 316 SS Similar Metal Weld under In-air and PWR Primary Loop Water Conditions," Argonne National Laboratory report, no. ANL/LWRS-15/02.

[14].S. Mohanty, W. K. Soppet, S. Majumdar and K. Natesan. 2016. Nuclear Engineering and Design. DOI:/10.1016/j.jnucmat.2016.01.034

[15].S. Mohanty, B. Barua, W. K. Soppet, S. Majumdar and K. Natesan. 2016, "Study the Cyclic Plasticity Behavior of 508 LAS under Constant, Variable and Grid-Load-Following Loading Cycles for Fatigue Evaluation of PWR Components," Argonne National Laboratory report, no. ANL/LWRS-16/03, (https://www.osti.gov/scitech/biblio/1331616).

[16].S. Mohanty, W. K. Soppet, B. Barua, S. Majumdar and K. Natesan. 2017. Experimental Mechanics. DOI:/10.1007/s11340-017-0278-y

[17]. B. Barua, S. Mohanty, W. K. Soppet, S. Majumdar and K. Natesan. 2017. "Fatigue Modeling of 508 LAS under Variable Amplitude Loading: A Mechanistic Based Analytical Approach," ASME Pressure Vessels and Piping Conference, PVP2017-65876.

[18].B. Schäfer, X. Song, P. Sonnweber-Ribic, H. ul Hassan and A. Hartmaier. 2019. Metals. DOI:/10.3390/met9030368

[19].S. Liu and G. Liang. 2017. Journal of Mechanics of Materials and Structures. 2017, 12, 439-455. DOI:/10.2140/jomms.2017.12.439
[20].G. Moeini, A. Ramazani, V. Sundararaghavan and C. Koenke. 2017. Materials Science and Engineering A 689. A 2017, 689, 89-95. DOI:/10.1016/j.msea.2017.02.033

[21].G. Moeini, A. Ramazani, S. Myslicki, V. Sundararaghavan and C. Könke. 2017. Metals. DOI:/10.3390/met7070265

[22]. Chaboche, G. Cordier and Dang Van K. 1979. "Modelization of the Strain Memory Effect on the Cyclic Hardening of 316 Stainless Steel", Proc. of 5th Structural Mech. in Reactor Technology (SMIRT 5), Berlin.

[23].N. Ohno and Y. Kachi, "Description of Stressand Strain-Controlled Cyclic Plastic Using the Cyclic Non-Hardening Region Model", 8th SMIRT Conf., paper no. L2/2, Brussels.

[24].M. A. Meggiolaro, H. Wu and J.T.P. De Castro. 2016. International Journal of Fatigue. DOI:/10.1016/j.ijfatigue.2015.07.027

[25].E. Tanaka. 1994. European Journal of Mechanics- A/Solids.

[26].M. A. Meggiolaro, J. T. P. De Castro and H. Wu. 2016. International Journal of Fatigue. DOI:/10.1016/j.ijfatigue.2015.08.030

[27].M.A. Meggiolaro, J. T. P. De Castro and H. Wu, et al. 2016. International Journal of Fatigue. DOI:/10.1016/j.ijfatigue.2015.08.031

[28].Z. Mroz. 1967. Journal of Mechanics and Physics of Solids. DOI://10.1016/0022-5096(67)90030-0

[29].H. Burlet and G. Cailletaud. 1986. Engineering Computations. DOI:/10.1108/eb023652

[30].J. C. Moosbrugger and D. L. McDowell. 1990. Journal of the Mechanics and Physics of Solids. DOI:/10.1016/0022-5096(90)90026-Z

[31].J. L. Chaboche and D. Nouailhas. 1989. ASME Journal of Engineering Materials and Technology. DOI:/10.1115/1.3226490

[32].J. L. Chaboche and D. Nouailhas. 1989. ASME Journal of Engineering Materials and Technology. DOI:/10.1115/1.3226484

[33].Y. Y. Jiang and H. Sehitoglu. 1994. International Journal of Plasticity. DOI:/10.1016/07496419(94)90015-9 
[34].M. Abdel-Karim and N. Ohno. 2000. Cite this article as : International Journal of Plasticity. DOI:/10.1016/S0749-6419(99)00052-2

Panagiotis J. Charitidis, "Viscoplastic Parametric

[35].N. Ohno and Y. Kachi. 1986. ASME Journal of Applied Mechanics. DOI:/10.1115/1.3171771

Analysis of Cylindrical Specimen Under Cyclic Behaviour", International Journal of Scientific

[36].N. Ohno. 1998. International Journal of Mechanics Sciences. DOI:/10.1016/S00207403(97)00053-2

Research in Science, Engineering and Technology (IJSRSET), Online ISSN : 2394-4099, Print ISSN : 2395-1990, Volume 8 Issue 1, pp. 75-82, January-

[37].J. L. Chaboche and G. Rousselier. 1983. ASME Journal Pressure Vessel Technology. DOI:/10.1115/1.3264257 February 2021. Available at doi : https://doi.org/10.32628/IJSRSET218111 Journal URL : http://ijsrset.com/IJSRSET218111

[38].J. Lemaitre and J. L. Chaboche. 1989. "Mechanics of Materials". Cambridge University Press, Cambridge

[39].Y. F. Dafalias and E. P. Popov. 1976. ASME Journal of Applied Mechanics. DOI:/10.1115/1.3423948

[40].N. T. Tseng and G. C. Lee. 1983. Journal of Engineering Mechanics. DOI://10.1061/(ASCE)07339399(1983)109:3(795)

[41].D. L. McDowell. 1985. ASME Journal of Applied Mechanics. DOI:/10.1115/1.3169044

[42].C.C Chu. 1984. Journal of the Mechanics and Physics of Solids. DOI:/10.1016/00225096(84)90008-5

[43].A. R. Khoei and N. Jamali. 2005. International Journal of Plasticity. DOI:10.1016/j.ijplas.2004.11.010

[44].M. Klisinski. 1988. ASME Journal of Engineering Mechanics. DOI:/10.1061/(ASCE)07339399(1988)114:4(563)

[45].S. J. Zakavi, M, Zehsaz and M. R. Eslami. 2010. Journal of Nuclear Engineering. DOI:/10.1115/1.3169044

[46].W. Prager. 1949. Journal of Applied Physics. DOI:/10.1063/1.1698348

[47].COMSOL Multiphysics Reference Manual, November 2019 